\title{
Construir a relação escola-comunidade educativa: uma abordagem exploratória no concelho de Almada
}

\author{
Mariana Gaio Alves \& Teresa Varela \\ Universidade Nova de Lisboa, Portugal
}

\begin{abstract}
Resumo
O artigo centra-se na temática da relação entre escola e comunidade educativa. Numa primeira parte, a temática é enquadrada e problematizada à luz quer da evolução de modelos de organização do sistema educativo português, quer de diversos contributos de reflexão e pesquisa, produzidos sobretudo em Portugal, mas também noutros países. Numa segunda parte, apresentam-se dados empíricos resultantes de um inquérito por questionário respondido por todas as escolas do concelho de Almada, o qual constitui a etapa exploratória de uma pesquisa de doutoramento. Por fim, na nota conclusiva, para além da sistematização dos resultados da reflexão produzida no artigo, apontam-se pistas de investigação futuras que permitam aprofundar a exploração da temática em análise.
\end{abstract}

Palavras-chave

Gestão escolar; Sistema educativo; Comunidades locais

\section{Nota Introdutória}

Este artigo explora a temática da relação entre escola e comunidade educativa, a qual assume grande relevância social e científica na atualidade, tendo em conta as tendências de evolução que vêm sendo identificadas no plano da organização e funcionamento do sistema educativo português. 
Como sublinha Ferreira (2003), nas últimas três décadas tem-se assistido à proliferação de noções como autonomia, contrato, projeto, participação e também comunidade, assim como à emergência de práticas e políticas de gestão da escola que envolvem a parceria entre instituições, serviços e profissionais de educação, saúde e serviço social. Tendo em conta este panorama, o objetivo geral deste artigo é o de produzir uma reflexão sobre os contornos da relação entre escola e comunidade educativa, mobilizando dados empíricos referentes a um contexto territorial específico: 0 concelho de Almada. Numa primeira parte, a temática é enquadrada e problematizada à luz, quer da evolução de modelos de organização do sistema educativo português, quer de diversos contributos de reflexão e pesquisa, produzidos sobretudo em Portugal, mas também noutros países. Numa segunda parte, apresentam-se dados empíricos resultantes de um inquérito por questionário respondido por todas as escolas do concelho de Almada, o qual constitui a etapa exploratória de uma pesquisa de doutoramento ${ }^{1}$. Por fim, na nota conclusiva, para além da sistematização dos resultados da reflexão produzida no artigo, apontam-se pistas de investigação futuras que permitam aprofundar a exploração da temática em análise.

\section{Contextualização e perspetiva evolutiva da relação escola- comunidade}

A relação entre escola e comunidade educativa vem assumindo uma centralidade crescente nas últimas décadas, quer enquanto alvo de atenção dos debates sociais e políticos, quer como objeto de pesquisa educativa. Esta situação tem origem em tendências de evolução na organização do sistema educativo, as quais, por seu turno, são indissociáveis de resultados da pesquisa educativa. Neste sentido, a relação entre escola e comunidade configura, simultaneamente, uma área de ação educacional e uma temática de investigação educativa que hoje se revestem de significativa relevância social e científica.

\section{Tendências evolutivas no plano internacional}

Como sublinham diversos autores (Epstein \& Sanders, 2000; Ferreira, 2003; Canário, 2005) reportando-se à evolução registada na América do Norte 
e em vários países europeus, a emergência do objeto de estudo 'escola' ocorre na década de 1980. Por um lado, constatava-se, na época, que a sociologia da educação estava muito frequentemente restrita ao escolar, mas sem considerar o próprio estabelecimento escolar como um objeto científico e como um nível de análise a explorar (Canário, 2005). Por outro lado, um conjunto de problemas emergentes nos sistemas de ensino massificados e a tendência para valorizar a ação dos estabelecimentos escolares nas suas especificidades para a resolução desses problemas originavam a necessidade de explorar este nível de intervenção e de análise.

Com efeito, na década de 1980 verificou-se que a expansão dos sistemas educativos, que se havia intensificado após o final da $2^{a}$ Guerra Mundial, coexistia com a permanência de desigualdades sociais no seu interior, ao mesmo tempo que aumentavam as taxas de insucesso e abandono escolares. Na verdade, na opinião de Zay (1996), a massificação da escola originou novos problemas, nomeadamente com a entrada de gerações de jovens provenientes de meios que contestam a cultura que a escola transmite e com problemas gerais da sociedade pelos quais se tende a imputar a responsabilidade à escola, como seja o insucesso escolar ou as dificuldades de inserção social e profissional dos jovens. No sentido de ultrapassar estes constrangimentos, seguiu-se uma evolução geral fazendo apelo à parceria, designadamente entre escola e pessoas e instituições das comunidades locais, de modo a suplantar problemas excessivamente complexos para serem resolvidos pela escola sozinha.

Assim, a expressão "escola em parceria" traduz uma mudança de paradigma relativamente à expressão "abertura à comunidade", revelando uma passagem da lógica burocrática baseada no cumprimento dos normativos para uma lógica de parceria baseada na negociação entre atores sociais a quem é reconhecido o poder de estabelecer contratos. Revela, ainda, a passagem de um paradigma linear e causal a um paradigma sistémico, reconhecendo que os problemas das escolas não podem ser tratados isoladamente de outros, tanto internos como externos ao sistema educativo (Zay, 1996). Noutros termos, trata-se de argumentar (como também defende Dias, 2003) que a abertura ao "meio" ou "à comunidade" marca o primeiro período da relação escola-comunidade, constituindo um esforço de aproximação entre a cultura escolar e as culturas dos alunos e suas famílias, 
sem contudo alterar a forma de a escola se organizar e funcionar. Ora, ao conceito de "escola aberta à comunidade", dominante durante mais de 20 anos, foi sucedendo o de "escola em parceria", no sentido de sugerir relações mais horizontais, aumentando o grau de responsabilização e de participação local e gerando novas formas de regulação social (Dias, 2003).

Neste sentido, a escola não pode mais ser entendida como uma organização social isolada, a qual se valida e justifica internamente. A escola deve ser encarada como uma organização social que se insere numa determinada comunidade, a qual tem de ser tida em conta na enunciação dos seus objetivos e perante a qual tem de se responsabilizar em termos de resultados. Assim, uma perspetiva atomística da educação é substituída por uma perspetiva sistémica, considerando-se a escola como um sistema aberto, que resulta de uma dissolução das fronteiras entre a escola e a comunidade envolvente (Branco, 2007). A expressão "envolver para desenvolver", adotada por Marques (2003) no seu estudo sobre parcerias educativas, é também ilustrativa desta tendência evolutiva.

Com efeito, no plano europeu, a partir da década de 1980, foram sendo implementadas reformas em matéria de autonomia, com ritmos e intensidades diversas nos vários países, sublinhando-se a necessidade de as escolas se abrirem mais à comunidade e valorizando práticas de participação democrática (Eurydice, 2007). Por exemplo, em Espanha, a Lei Orgânica do Direito à Educação de 1985 estabelece a necessidade de estarem presentes, no processo de decisão da escola, todas as partes da comunidade educativa, ao mesmo tempo que, em França, o regime jurídico de 1985 estabeleceu normas para a abertura da escola à comunidade educativa.

Durante os anos 90, continuou em aberto a concessão de uma maior abertura aos participantes locais, acrescendo a esta preocupação uma outra centrada na gestão eficiente dos fundos públicos. Deste modo, a autonomia encerra uma dupla vertente, englobando, por um lado, a necessidade de descentralização de responsabilidades para um nível mais próximo do campo de ação, apelando à intervenção da comunidade educativa, e, por outro, a lógica de numa nova gestão pública que garanta uma melhor utilização dos recursos públicos (Eurydice, 2007). Neste cenário, em países como República Checa, Polónia, Eslováquia, Estados Bálticos e do Norte da Europa, as reformas relativas à autonomia passaram a estar fortemente ligadas aos 
princípios da prestação de contas e avaliação dos resultados, garantindo que as decisões tomadas asseguram a melhor utilização dos recursos públicos, para além da concessão de novas liberdades aos participantes locais (Eurydice, 2007).

No início do novo milénio, constata-se o reforço de políticas de autonomia em países que já as haviam implementado, procurando-se ultrapassar as resistências encontradas pelas primeiras reformas educativas desenvolvidas (veja-se os exemplos de Espanha, Letónia, Eslovénia e França, entre outros), enquanto outros país, como a Alemanha, Lituânia, Luxemburgo e Roménia, começam neste período cronológico a ponderar o reforço da autonomia escolar (Eurydice, 2007).

Em síntese, a mudança educacional impôs uma redefinição do entendimento do estabelecimento escolar, de uma unidade administrativa que prolongava a administração centralizada da educação para uma organização singular com especificidades locais em função das quais são reconstruídas as normas e a cultura do sistema educativo em que se insere.

Do ponto de vista da investigação, privilegiar a escola como objeto de estudo insere-se "quer numa tendência de alargamento do campo de investigação (que ultrapassa as fronteiras do escolar), quer numa nova perspetiva de ler e interpretar os fenómenos escolares" (Canário, 2005, pp. 52-53). Ou seja, significa admitir o pressuposto de que em cada escola, pela ação dos atores nela intervenientes e em função das particularidades do respetivo contexto, são reconstruídas as orientações globais do sistema educativo.

\section{O caso português}

A evolução em matéria de modelos de gestão escolar em Portugal enquadra-se nas tendências identificadas a nível europeu. A autonomia e a abertura à comunidade educativa têm vindo a constituir palavras-chave de uma organização do sistema educativo que se pretende mais descentralizada, democrática e com melhores resultados educativos, desde a mudança política portuguesa de 1974. Se, durante o período do Estado Novo (1926-1974), a administração da educação em Portugal assumiu fortes características centralizadoras, constata-se que, no período após o 25 de abril de 1974, 
apesar dos apelos à democraticidade e à participação dos diversos atores no processo educativo, a alteração da lógica centralizadora revelou-se difícil, não tendo correspondido plenamente a um processo de descentralização e partilha de poderes que se considera necessário e amplamente justificado (Lima, 1998). Ou seja, o processo de abertura à comunidade encontra diversas resistências, não traduzindo ainda um verdadeiro processo de estabelecimento de parcerias entre as escolas e as comunidades locais que as envolvem.

Em meados da década de 1980, quando, a nível europeu, se verifica o início da intensificação das tendências para a autonomia das escolas, é promulgada em Portugal a Lei de Bases do Sistema Educativo (1986), na qual também se estabelece que o sistema de ensino deverá "descentralizar, desconcentrar e diversificar as estruturas e ações educativas, de modo a proporcionar uma correta adaptação à realidade, um elevado sentido de participação das populações, uma adequada inserção no meio comunitário, contribuindo para a correção das assimetrias de desenvolvimento regional e local" (alíneas g e $\mathrm{h}$ do artigo $3 .{ }^{\circ}$ ). Simultaneamente, estudos levados a cabo pela Comissão de Reforma do Sistema Educativo (CRSE) sugeriram alterações na administração escolar, no sentido de serem transferidos determinados poderes e funções do nível central para o local, reconhecendo a escola como centro nevrálgico do sistema educativo e a comunidade local como parceiro indispensável na tomada de decisões (Sousa, 2000). Na opinião de Afonso (1999), a aplicação desta intenção de descentralização foi limitada pela excessiva normalização do poder central, originando, com 0 passar dos anos, a desmobilização dos atores locais escolares e justificando as tomadas de decisão a nível central. Algumas pesquisas educativas publicadas neste período realçaram, igualmente, a fraca intensidade das relações entre escola e comunidade no caso português.

Para Alves et al. (1997), no nosso país, tanto o envolvimento das famílias, das autarquias, dos movimentos associativos e das empresas na escola é considerado deficiente, como também é escasso o conhecimento que as comunidades científicas e educativas têm sobre as práticas reais das escolas. Num estudo realizado na Gafanha da Nazaré, Arroteia, Pardal, Costa, Martins, e Neto Mendes (1997) procuraram conhecer a interação escola-comunidade tendo em conta a identificação das características e 
dinâmicas sociais do território e a adequação das respostas escolares aos interesses socioeconómicos da comunidade local. Os autores verificaram a existência de uma escola concebida sem atendimento à especificidade da população local, não se verificando articulação com as necessidades próprias de uma sociedade em mudança e não se observando qualquer indício de transformação por parte das empresas locais que apelasse a possíveis ligações entre o mundo do trabalho e a educação/formação.

Apesar disso, do ponto de vista legislativo, é a partir dos anos 80 que a relação escola-comunidade educativa emerge como uma dimensão relevante no quadro normativo que regulamenta o sistema educativo português. Neste sentido, segundo Branco (2007), é no Decreto-Lei n. ${ }^{\circ} 115$ A/98, de 4 de maio, que é feita, pela primeira vez, referência explícita a um conceito mais alargado de comunidade educativa afirmando a "representatividade dos órgãos de administração e gestão da escola, garantida pela eleição democrática de representantes da comunidade educativa" (artigo 4, alínea c). Este decreto de 1998 previa a introdução de um órgão de administração intitulado Assembleia de Escola, o qual deveria ser constituído em partes iguais por representantes do pessoal docente e por outros representantes (pais e encarregados de educação, alunos, pessoal não docente e autoridades locais), através do qual se assegurava a presença de elementos da comunidade educativa envolvente na organização escolar. É que, de acordo com Formosinho (2007), este decreto procurou reconciliar as diferentes posições sobre participação e autonomia das escolas em debate durante a década anterior à sua promulgação. Uma das posições, defendida pelas Associações de Pais, sublinhou a necessidade de ultrapassar o modelo de administração das escolas públicas apenas por professores e, consequentemente, enfatizou a necessidade de se criarem órgãos de administração compostos por representantes de pais e da comunidade e com o poder de selecionar/nomear o Diretor da escola pública. Outra posição, também originária do período após 25 de abril e defendida pelos sindicatos dos professores, acentuava a necessidade de as escolas públicas serem administradas pelos respetivos professores que entre eles elegem o Diretor da escola.

A avaliação do processo de implementação do Decreto-Lei 115-A/98 evidenciou as dificuldades de reforço de autonomia, apontando para um 
excesso de intervenção da administração regional e central, com grande controlo nos textos dos regulamentos internos, modificados na larga maioria (90\%) das escolas inquiridas e com a quase inexistência de assinaturas de contratos de autonomia (Barroso, 2001, cit. por Lima, Pacheco, Esteves, \& Canário, 2006). Lima et al. (2006) argumentam que em 2001 as escolas portuguesas se encontravam no grau zero de autonomia contratualizada, situação que consideram congruente com uma política de educação de tipo centralizado-desconcentrado. Algumas pesquisas educativas publicadas após a implementação deste modelo de gestão escolar evidenciaram as potencialidades do estreitamento das articulações entre escola e comunidade envolvente, ainda que também refiram as dificuldades e resistências nesse relacionamento.

Num estudo que teve como objetivo implementar uma proposta de cooperação entre diferentes parceiros locais, reconfigurando a organização educativa e social com forte intervenção das políticas locais, Lopes (2003) concluiu ser possível desenvolver práticas socioeducativas, organizadas em cooperação e com diferentes parcerias, as quais produzem alterações concretas na proteção e reedificação de património artístico e cultural local e, também, na melhoria das condições físicas na escola. Numa outra perspetiva, Tavares (2007) procurou construir e dinamizar, num estudo local, uma ligação entre a escola velha esquecida e a nova escola recriada, procurando garantir que não se perca a memória associada aos sítios e pessoas que lhe deram forma e vida. Concluiu que o conhecimento endógeno do lugar e a sua valorização através de projetos envolventes são vias conducentes ao desenvolvimento do local.

Já o estudo de Rodrigues (2008) se baseou numa tentativa de aprofundar e compreender a dinâmica da estratégia em parceria em contexto local, procurando investigar se a mesma é um instrumento eficaz e articulador das medidas de intervenção local e se contribui para o fomento de mecanismos de cooperação e interajuda entre os atores envolvidos no processo de desenvolvimento local. Concluiu que o envolvimento da sociedade civil e a maior autonomia de desenvolvimento local só poderão produzir resultados eficazes e adequados se os atores tomarem consciência do trabalho em parceria e o interiorizarem nas suas culturas organizacionais e nas suas práticas. Constatou ainda que o envolvimento e dinamização das 
estratégias delineadas na parceria dependem da coordenação, requerendo um envolvimento e capacitação dos parceiros locais intervenientes. O planeamento das ações de melhoria e a delineação de estratégias envolvem os atores, num esforço de cumprimento das metas e objetivos a que se propuseram.

Também estudando e analisando parcerias num contexto local, Marques (2003) evidencia o modo como as parcerias, embora vejam formalmente reconhecido o seu papel social e educativo, continuam a ocupar um lugar secundário na vida da escola, apresentando um dinamismo entorpecido por limitações legislativas e por autonomias não assumidas, constituindo-se mais como complementos do que como orientadoras da vida da escola e da comunidade. Num outro estudo (Branco, 2007) com o objetivo de saber até que ponto o ideal de educação democrática exige o aprofundamento da comunidade escolar, no sentido da comunidade educativa, concluiu-se que, apesar do novo regime de autonomia conceder à escola um lugar central, incentivando a construção de uma autonomia de escola baseada no diálogo com a comunidade educativa envolvente, não se vislumbram dinâmicas escolares com efeitos a nível da comunidade local.

$\mathrm{Na}$ avaliação que a OCDE (2007) produziu das relações da escola com a comunidade envolvente, em Portugal, considera-se também que a representação dos diferentes grupos da comunidade educativa, nomeadamente pais e encarregados de educação, é bastante resumida e que o recrutamento dos seus representantes é feito, essencialmente, junto de grupos sociais reduzidos e, não raro, de pais e mães que são professores. De facto, embora assinale a inexistência de dados extensivos (mesmo que apenas de mera descrição estatística), Silva (2006) sustenta, a partir das suas pesquisas, que em múltiplas situações se verifica que são pais que exercem atividade profissional como docentes que assumem mais frequentemente e intensamente a participação das famílias nas escolas, designadamente como protagonistas na liderança de Associações de Pais.

Por outro lado, a OCDE (2007) refere que o envolvimento com empresas está relacionado essencialmente com o desenvolvimento da formação profissional, de que é exemplo a articulação das escolas com ensino secundário com empresas da região tendo como objetivo a escolha da oferta de cursos e a concretização de estágios para os alunos. É também 
frequente o estabelecimento de relações com vista ao desenvolvimento de estratégias de angariação de fundos e de apoio aos projetos da escola, junto dos pais, das autarquias locais e empresas, criando por vezes uma rede ativa de colaboração e parceria entre a escola e o meio social envolvente.

Assim, globalmente, infere-se que não basta salvaguardar a participação formal dos vários elementos da comunidade educativa prevendo o seu assento nos órgãos de gestão das escolas e a sua participação na elaboração do projeto educativo, sendo necessária alguma liderança na implementação de dinâmicas que potencializem as relações entre as escolas e as instituições das comunidades locais envolventes e que promovam a mobilização dos recursos existentes.

Mais recentemente, veio a ser promulgado, em Portugal, no ano de 2008, o atual regime de autonomia, administração e gestão dos estabelecimentos públicos da educação pré-escolar e dos ensinos básico e secundário, que procura reforçar a participação das famílias e comunidades na direção estratégica dos estabelecimentos de ensino. Pretende-se concretizar este objetivo através da instituição de um novo "órgão de direcção estratégica em que têm representação o pessoal docente e não docente, os pais e encarregados de educação (e também os alunos, no caso dos adultos e do ensino secundário), as autarquias e a comunidade local, nomeadamente representantes de instituições, organizações e atividades económicas, sociais, culturais e científicas" (Decreto-Lei n. ${ }^{\circ}$ 75/2008, de 22 de abril Preâmbulo). A este órgão colegial de direção - designado Conselho Geral cabe a aprovação das regras fundamentais de funcionamento da escola (regulamento interno), as decisões estratégicas e de planeamento (projeto educativo, plano de atividades) e o acompanhamento da sua concretização (relatório anual de atividades). Além disso, confia-se a este órgão a capacidade de eleger e destituir o Diretor, que, por conseguinte, lhe tem de prestar contas. Globalmente, as principais alterações introduzidas por este Decreto-Lei são a substituição da Assembleia Geral pelo Conselho Geral, com reforço na representação da comunidade educativa, e a alteração da lógica de gestão escolar, que de colegial passa a unipessoal (centrada na figura do Diretor).

Ora, na perspetiva de Lima (2009), esta redução do princípio da colegialidade, associando-a sobretudo a órgãos de natureza consultiva e 
concentrando poderes, é interpretada como uma evolução negativa, a qual origina uma autonomia de tipo gerencial e técnico-administrativo desvinculada da democratização do governo das organizações escolares. Para o autor, temos vindo a assistir, desde o período que se seguiu ao 25 de abril de 1974, a uma perda de protagonismo e legitimidade da categoria "gestão democrática das escolas" especialmente a favor da categoria "autonomia das escolas".

Na perspetiva do Conselho Nacional de Educação também se indica que, no atual modelo da avaliação externa, a participação dos representantes do poder local está reservada à reunião inicial, onde são apresentados os pontos fortes e fracos das unidades de gestão, e à reunião com o Conselho Geral, onde os autarcas têm também assento (CNE, 2010). Para o CNE, este distanciamento não resulta exclusivamente do modelo utilizado, sendo também reflexo de um certo afastamento da comunidade envolvente, existente em muitas escolas. Assinala-se, no entanto, que as estruturas representativas dos encarregados de educação, nomeadamente as Associações de Pais e Encarregados de Educação (APEE), parecem ter algum envolvimento na vida escolar em geral, embora ainda aquém do desejável.

\section{Contextualização da pesquisa}

Tendo em conta o panorama traçado, diversas interrogações emergem. O nosso objetivo, neste artigo, é contribuir para refletir sobre os sentidos atribuídos à relação entre escola e comunidade educativa, mobilizando dados empíricos recolhidos junto das escolas do concelho de Almada. Trata-se, portanto, de explorar a perspetiva das próprias escolas na voz dos seus Diretores, cientes, por um lado, de que estes são atores fulcrais da relação escola-comunidade, mas, por outro, de que as escolas não são o único ator a configurar esta relação, a qual depende também das dinâmicas e instituições locais, assim como dos quadros macro de orientações de política educativa.

Apresentam-se dados que respeitam, pois, a um contexto territorial específico e circunscrito, o que assenta em dois pressupostos. Um pressuposto corresponde à nossa concordância com a afirmação de que o 
estudo do local, em educação, necessita de um contexto concreto, que possa funcionar como plataforma de observação das políticas públicas e das dinâmicas socioeducativas locais (Ferreira, 2003). O outro pressuposto é o de que privilegiamos abordagens, no estudo da regulação dos sistemas educativos, que permitam explorar o modo como as orientações globais de política educativa são reconstruídas e reinterpretadas a nível local. Em trabalho de pesquisa anterior, centrado num outro tema educativo, tivemos oportunidade de argumentar, precisamente, que as políticas educativas são, afinal, um resultado contingente das inter-relações entre vários atores individuais e coletivos em diversos níveis (internacionais, nacionais, locais e institucionais) de decisão (Alves, 2010).

Neste artigo apresentam-se dados resultantes de um questionário aplicado no final do ano letivo 2009/10, tendo sido nesse mesmo ano que a maioria dos Conselhos Gerais e Diretores eleitos iniciou funções ao abrigo do Decreto-Lei de 2008 que configura o atual modelo de gestão escolar. Por isso, convém salientar que o questionário é aplicado num contexto de mudança em que a atenção sobre a temática da relação escola-comunidade educativa é reforçada, na medida em que a presença de membros da comunidade nos órgãos de gestão escolar é valorizada, contribuindo para promover a participação de comunidade das autonomias escolares.

\section{A relação escola-comunidade educativa: a perspetiva das escolas do concelho de Almada}

Nesta segunda parte do artigo, apresentam-se os dados resultantes do questionário respondido por todas as escolas do concelho de Almada. Começamos por explicitar brevemente os procedimentos metodológicos adotados na aplicação do questionário para, em segundo lugar, caracterizar genericamente as escolas, os alunos, a oferta formativa, bem como os órgãos de gestão das escolas inquiridas. Por fim, a apresentação de dados organizase de modo a responder às questões: $O$ que entendem as escolas por relação com a comunidade? E como a praticam? Que articulações existem entre cultura organizacional e tipo de relação com a comunidade educativa? 


\section{Breve nota metodológica}

Os dados empíricos que em seguida se apresentam resultam de um inquérito por questionário respondido por todos os Agrupamentos e Escolas Não Agrupadas (A/ENA) do concelho de Almada, constituindo um estudo exploratório da relação entre escola e comunidade educativa neste território específico. Não obstante, os dados permitem levantar questionamentos e enunciar reflexões que podem ser pertinentes relativamente a outros territórios.

O questionário foi aplicado on-line em abril de 2010 e respondido por todos os Diretores dos A/ENA do concelho de Almada, sendo que as escolas participantes no estudo coincidem com o universo das escolas públicas do concelho. Foi enviado um e-mail explicitando o objetivo do questionário, o modo de preenchimento e a garantia da confidencialidade. No tratamento dos dados foram utilizados procedimentos estatísticos descritivos, que consistiram no cálculo de frequências absolutas e relativas, de medidas de tendência central, de medidas de dispersão e cruzamentos simples. O programa informático utilizado foi o SPSS (Statistical Package for Social Science), versão 18.0 para Windows.

\section{Quadro 1 - Caracterização geral dos Agrupamentos/Escolas Não Agrupadas inquiridos/as}

\begin{tabular}{|c|c|c|c|c|c|c|c|c|c|c|c|c|c|c|c|c|c|c|c|}
\hline \multirow{3}{*}{ Tip. } & \multirow{3}{*}{ Oferta } & \multicolumn{7}{|c|}{ Elementos CG } & \multicolumn{3}{|c|}{ Docentes } & \multicolumn{8}{|c|}{ Alunos } \\
\hline & & \multirow[t]{2}{*}{ PD } & \multicolumn{2}{|c|}{ PND } & \multirow[t]{2}{*}{ APEE } & \multirow[t]{2}{*}{ Aut } & \multirow[t]{2}{*}{ Com. } & \multirow[t]{2}{*}{ Als } & \multirow[t]{2}{*}{ Total } & \multirow[t]{2}{*}{ CEF } & \multirow[t]{2}{*}{ CP } & \multirow[t]{2}{*}{$\begin{array}{l}\mathrm{Jl} / \\
1^{\circ} \mathrm{C}\end{array}$} & \multirow[t]{2}{*}{$2^{\circ} \mathrm{C}$} & \multirow[t]{2}{*}{$3^{\circ} \mathrm{C}$} & \multirow[t]{2}{*}{ E.S. } & \multirow[t]{2}{*}{ CEF } & \multirow[t]{2}{*}{ PCA } & \multirow[t]{2}{*}{ CP } & \multirow[t]{2}{*}{ Total } \\
\hline & & & A.U & A.I & & & & & & & & & & & & & & & \\
\hline 3 & 1,3 & 7 & 1 & 1 & 4 & 3 & 3 & & 200 & 0 & 0 & 1236 & 584 & 158 & 0 & 0 & 15 & 0 & 1993 \\
\hline 3 & $1,2,3,4,5$ & 8 & 1 & 1 & 3 & 3 & 3 & 2 & 212 & 13 & 23 & 603 & 240 & 369 & 367 & 30 & 13 & 47 & 1669 \\
\hline 3 & 1,2 & 7 & 1 & 1 & 6 & 3 & 3 & & 93 & 9 & 0 & 478 & 202 & 175 & 0 & 16 & 0 & 0 & 871 \\
\hline 3 & 1,5 & 7 & 1 & 1 & 6 & 3 & 3 & & 132 & 0 & 0 & 504 & 923 & 125 & 0 & 0 & 0 & 0 & 1552 \\
\hline 3 & 1 & 7 & 1 & 1 & 6 & 3 & 3 & & 79 & 0 & 0 & 365 & 290 & 328 & 0 & 0 & 0 & 0 & 983 \\
\hline 3 & $1,2,3$ & 7 & 1 & 1 & 6 & 3 & 3 & & 177 & 11 & 0 & 1016 & 468 & 292 & 0 & 26 & 45 & 0 & 1847 \\
\hline 3 & $1,2,3$ & 8 & 1 & 1 & 5 & 3 & 3 & & 134 & 7 & 0 & 565 & 312 & 398 & 0 & 14 & 12 & 0 & 1301 \\
\hline 3 & $1,2,3$ & 7 & 0 & 2 & 6 & 3 & 3 & & 90 & 0 & 0 & 706 & 295 & 369 & 0 & 30 & 77 & 0 & 1477 \\
\hline 3 & $1,2,3$ & 8 & 1 & 1 & 5 & 3 & 3 & & 61 & 11 & 0 & 557 & 248 & 244 & 0 & 25 & 31 & 0 & 1105 \\
\hline 3 & $1,3,4,5$ & 8 & 1 & 1 & 5 & 2 & 2 & 2 & 162 & 0 & 9 & 808 & 266 & 220 & 165 & 0 & 35 & 23 & 1517 \\
\hline 3 & $1,2,3$ & 7 & 1 & 1 & 4 & 3 & 3 & & 81 & 10 & 0 & 361 & 122 & 151 & 0 & 35 & 12 & 0 & 681 \\
\hline 3 & 1 & 7 & 0 & 2 & 5 & 3 & 4 & & 104 & 0 & 0 & 800 & 350 & 295 & 0 & 0 & 0 & 0 & 1445 \\
\hline 3 & $1,2,4$ & 7 & 1 & 1 & 3 & 2 & 2 & 3 & 94 & 21 & 33 & 0 & 0 & 247 & 267 & 49 & 0 & 137 & 700 \\
\hline 4 & $1,4,5$ & 7 & 0 & 2 & 4 & 3 & 3 & 2 & 153 & 0 & 66 & 0 & 30 & 35 & 1098 & 0 & 0 & 244 & 1407 \\
\hline 4 & $1,2,4,5$ & 7 & 2 & 0 & 4 & 3 & 3 & 2 & 132 & 0 & 0 & 0 & 16 & 190 & 354 & 20 & 0 & 231 & 811 \\
\hline 5 & $1,2,4$ & 7 & 2 & 0 & 4 & 3 & 3 & 2 & 93 & 33 & 20 & 0 & 0 & 434 & 351 & 57 & 0 & 32 & 874 \\
\hline 5 & $1,2,4$ & 8 & 1 & 1 & 4 & 3 & 3 & 2 & 107 & 20 & 42 & 0 & 0 & 301 & 465 & 29 & 0 & 179 & 974 \\
\hline 5 & $1,2,4,5$ & 7 & 1 & 1 & 5 & 2 & 3 & 2 & 207 & 7 & 0 & 0 & 0 & 420 & 586 & 56 & 0 & 75 & 1137 \\
\hline 5 & $1,2,4,5$ & 7 & 1 & 1 & 4 & 3 & 3 & 2 & 134 & 15 & 32 & 0 & 0 & 381 & 532 & 36 & 0 & 69 & 1018 \\
\hline 5 & $1,2.4,5$ & 7 & 1 & 1 & 4 & 3 & 3 & 2 & 117 & 30 & 0 & 0 & 0 & 410 & 440 & 41 & 0 & 74 & 965 \\
\hline
\end{tabular}




\section{As escolas, os alunos e a oferta formativa}

Constata-se que no concelho de Almada existe uma forte presença dos Agrupamentos Verticais, os quais constituem mais de metade (13) das 20 escolas. A maior parte dos A/ENA (12) têm mais de 1000 alunos, sendo que 7 têm entre 1000 a 1500 alunos e 5 podem ser considerados A/ENA de grande dimensão, por serem frequentados por mais de 1500 alunos. Os restantes (8) são frequentados por menos de 1000 alunos. O Agrupamento com o corpo discente mais reduzido apresenta 681 alunos.

Utilizando o número de alunos como instrumento de medida, os dados recolhidos permitem, ainda, caracterizar o peso relativo de cada nível ou ciclo de ensino, por tipologia. Naturalmente, nos Agrupamentos Verticais, os sectores do pré-escolar e do $1^{\circ}$ ciclo abrangem 48,6\%, constituindo-se como o setor com maior expressão, ultrapassando o $2^{\circ}$ e $03^{\circ}$ ciclos, quer isoladamente, quer o conjunto de ambos, que perfaz $46,6 \%$. Estes dados coincidem, como era expectável, com os que são divulgados pela Câmara Municipal de Almada², a qual apresenta, relativamente ao total de alunos do jardim de infância ao ensino secundário, uma maior percentagem até ao final do $1^{\circ}$ ciclo $(37,5 \%)$, relativamente ao $2^{\circ}$ ciclo $(17 \%)$ e $3^{\circ}$ ciclo $(24,5 \%)$, em 2008/09. Também a nível nacional ${ }^{3}$ os setores do pré-escolar e $1^{\circ}$ ciclo abrangem $59,5 \%$ do total de alunos matriculados até ao final do $3^{\circ}$ ciclo. Constata-se, ainda, que a componente do ensino secundário no Agrupamento Vertical é muito reduzida, registando apenas 4,8\%, o que corresponde a três unidades de Agrupamentos/Escolas Não Agrupadas de ensino, sendo que duas destas integram no seu projeto curricular todos os ciclos de estudo. Nas escolas com $2^{\circ}$ e $3^{\circ}$ ciclo e ensino secundário, observa-se algum desequilíbrio, sendo o número de alunos do $2^{\circ}$ ciclo bastante reduzido $(2,7 \%$ do total). É interessante observar que é superior a expressão do ensino secundário nestas escolas $(84,3 \%)$, relativamente às escolas secundárias com $3^{\circ}$ ciclo $(55,0 \%)$.

$\mathrm{Na}$ oferta formativa, constata-se a oferta de Cursos de Educação Formação (CEF) em catorze unidades de ensino. Estes cursos "destinam-se, preferencialmente, a jovens com idade igual ou superior a 15 anos, em risco de abandono escolar ou que já abandonaram antes da conclusão da escolaridade de 12 anos, bem como àqueles que, após conclusão dos 12 anos de escolaridade, não possuindo uma qualificação profissional, 
pretendam adquiri-la para ingresso no mundo do trabalho" (Despacho conjunto n. ${ }^{\circ} 453 / 2004^{4}$ ). Observa-se, ainda, que, em oito agrupamentos, foram criadas turmas de Percursos Curriculares Alternativos (PCA), compostas por alunos até aos 15 anos que se "apresentem em qualquer das seguintes situações: problemas de integração na comunidade escolar; Ameaça de risco de marginalização, de exclusão social ou abandono escolar; Registo de dificuldades condicionantes da aprendizagem nomeadamente: forte desmotivação, elevado índice de abstenção, baixa autoestima e falta de expectativas relativamente à aprendizagem e ao futuro, bem como o desencontro entre a cultura escolar e a sua cultura de origem", com o mesmo tipo de objetivos (Despacho normativo $n^{\circ} 01 / 2006^{5}$ ).

\section{Os órgãos de gestão da escola e as Associações de Pais e Encarregados de Educação}

Relativamente aos órgãos de gestão, constata-se que a totalidade das escolas do concelho de Almada é dirigida por um Diretor (cumprindo a legislação em vigor, designadamente o Decreto-Lei n. $\left.{ }^{\circ} 75 / 2008\right)$, tendo todos eles entrado em função em 2009/2010, com exceção de um, que está em exercício desde 2008

Reportando-nos aos anos anteriores, constata-se que dezasseis dos atuais Diretores tiveram anteriormente funções de gestão, ou como Presidentes de Conselho Executivo (12), ou como Presidentes da Comissão Administrativa Provisória (2), ou como Vice-Presidentes (1), ou ainda como Assessores da Direção (1). Apenas quatro dos atuais Diretores não têm qualquer experiência prévia no exercício de funções de direção e gestão.

Verifica-se, assim, uma certa estabilidade ao nível dos órgãos de gestão, característica comum a quase todas as unidades participantes no estudo e que revela um certo nível de continuidade e um eventual gosto pela administração educacional: seis dos atuais Diretores encontram-se em funções de gestão há mais de 15 anos, dois exercem-nas há entre 11 e 15 anos, e seis há entre 5 e 10 anos.

O Conselho Geral é composto por um número de elementos estabelecido por cada Agrupamento/Escola Não Agrupada, nos termos do respetivo regulamento interno, devendo ser um número ímpar não superior a 
21, cumprindo também o que está previsto no art. ${ }^{\circ} 12$ do Decreto-Lei n. ${ }^{\circ}$ 75/2008. Constata-se que o número de elementos que constituem o Conselho Geral varia de 19 (3 A/ENA) a 21 (17 A/ENA).

No que respeita às Associações de Pais e Encarregados de Educação, os dados recolhidos permitem-nos concluir que este tipo de associação foi constituída durante $O$ ano letivo anterior em cinco das unidades participantes neste estudo. Em dez outros A/ENA, as respetivas APEE foram criadas entre 1988 e 2008. Nos casos restantes, os atuais Diretores não referem ou desconhecem o ano da constituição da APEE do seu A/ENA. Em quase todas as unidades, indica-se que a APEE participa em algumas atividades que constam do Plano Anual de Atividades do Agrupamento/Escola. Ainda que treze dos Diretores afirmem apoiar a constituição de APEE e onze declarem disponibilizar sempre os recursos necessários ao funcionamento da mesma, constata-se que só uma pequena parte dos pais e encarregados de educação estão associados, variando o número de pais associados nos A/ENA participantes entre 8 e 81 (sendo em média de 24,5). Estes dados indiciam uma frágil representatividade dos associados das APEE face ao número (muito mais elevado) de alunos das escolas.

\section{O que entendem as escolas por relação com a comunidade? E como a praticam?}

Tendo em conta os dados recolhidos, constata-se que as escolas entendem a relação com a comunidade educativa numa lógica de abertura, como um conjunto de práticas partilhadas com alguns elementos da comunidade, preferencialmente pais e encarregados de educação. Apenas quatro dos Diretores afirmam envolver sempre a comunidade educativa na avaliação interna e apenas cinco procuram auscultar sempre da possibilidade de parcerias com instituições e empresas da região, de acordo com o projeto educativo do Agrupamento. Esta situação poderá não ser específica do território de Almada, uma vez que o Conselho Nacional de Educação (2010), no parecer sobre a avaliação externa, indica que a participação dos representantes do poder local está habitualmente reservada apenas à reunião inicial, onde são apresentados os pontos fortes e fracos das unidades de gestão, e ainda à reunião com o Conselho Geral, onde os autarcas têm também assento. Considera a mesma entidade que este distanciamento não 
resulta exclusivamente do modelo de avaliação, sendo também reflexo de um certo afastamento da comunidade envolvente existente em muitas escolas.

Importa ainda salientar que as respostas à questão sobre o modo como a escola realiza a auscultação das necessidades de articulação com o meio envolvente são bastante variadas. Assim, esta auscultação é realizada pela equipa responsável pelo projeto educativo em cinco Agrupamentos/ Escolas Não Agrupadas, num pequeno conjunto (3) apenas pelo Diretor ou por alguém por ele indicado, também num pequeno conjunto (3) pela equipa dos cursos CEF e cursos profissionais (CP), e nos restantes A/ENA (9) por vários destes protagonistas em simultâneo. Daqui se depreende que nem sempre a comunidade local e a autarquia são envolvidas na construção de um plano de articulação entre a escola e o meio, estando as decisões aparentemente centradas na escola, ou isoladamente na figura do Diretor, ou em grupos de trabalho responsabilizados para essa tarefa.

Enquanto órgão responsável pela decisão de estabelecimento de parcerias com a comunidade envolvente, os responsáveis pela gestão indicam: apenas o Diretor (7); o Diretor e o Conselho Geral (1); o Diretor e o Conselho Pedagógico (1); o Diretor, o Conselho Local de Educação e o Conselho Pedagógico (1); e o Diretor, o Conselho Geral e o Conselho Pedagógico (10). Verifica-se, assim, que onze dos vinte A/ENA envolvem o Conselho Geral nesta decisão, mas que em alguns a mesma é realizada de forma isolada.

Os documentos orientadores do estabelecimento relativamente a parcerias e protocolos com a comunidade educativa são, essencialmente, o projeto educativo do Agrupamento/Escola Não Agrupada (5), o projeto educativo em conjunto com o projeto de intervenção do Diretor (5), estes documentos associados ao projeto curricular de escola (4) ou a outro tipo de documentos produzidos internamente, como sejam o relatório da avaliação interna, relatório dos cursos profissionais e relatório dos cursos de educação e formação (3). Num pequeno número de casos, o documento orientador corresponde exclusivamente ao projeto de intervenção do Diretor (3).

A forma como as escolas praticam a relação com a comunidade educativa manifesta-se preferencialmente junto das APEE, que, em quase metade (9) das escolas, são a entidade promotora das atividades de enriquecimento curricular do $1^{\circ}$ ciclo (AECs) e da Componente de Apoio à 
Família (CAF) no pré-escolar. Também em quase metade (9) dos A/ENA se afirma que os pais e encarregados de educação participam nas atividades da escola.

Algumas escolas, numa lógica de parceria, desenvolvem formas de articulação com empresas locais, que respondem à necessidade de colocação em estágios de alunos dos cursos profissionais e dos cursos de educação e formação (10) ou à necessidade de apoio, com recursos materiais e técnicos, aos alunos com Necessidades Educativas Especiais (NEE) (4).

\section{Que articulações existem entre cultura organizacional e tipo de relação com a comunidade educativa?}

De acordo com Sousa (2006, p. 160), pode definir-se cultura organizacional como "o cimento que dá significado e coerência a um grupo/organização e orienta as suas ações presentes e futuras". A cultura concede uma identidade própria à organização, norteia a variedade individual para comportamentos conciliáveis com um objetivo comum, responde às necessidades de ordem, previsibilidade e segurança por parte dos indivíduos e dos grupos e possibilita lidar com a incerteza, quer no cumprimento das tarefas em comum, quer quanto ao posicionamento face ao exterior. Assim, o tipo de cultura predominante numa organização influencia o desenvolvimento de temas comportamentais como o tipo de autoridade considerado legítimo, o tipo de motivação para o trabalho, o tipo de liderança dominante, o relacionamento entre grupos, a forma de lidar com o conflito, com as regras e as prioridades para os novos membros.

Sousa (2006) identifica quatro tipos de cultura organizacional: autocrática (poder); burocrática (papel); realização; e apoio. A organização orientada por uma cultura de poder baseia-se na desigualdade de acesso aos recursos (privilégios, condições de trabalho, segurança), sendo este controlado por quem manda. Na cultura burocrática, o poder do líder é substituído por um conjunto de estruturas e procedimentos. Estes protegem os subordinados e dão estabilidade à organização. Os deveres e recompensas dos membros estão definidos e são objeto de um contrato explícito entre a organização e o indivíduo. Tanto a cultura autocrática como a burocrática dependem do uso de penalizações e de recompensas externas ao trabalho, em si, para motivar as pessoas. 
$\mathrm{Na}$ cultura de realização, o gosto pelo trabalho e a interação com colegas e clientes constituem recompensas intrínsecas, mais qualitativas que quantitativas, e advêm da natureza das tarefas e do contexto em que têm lugar. É uma cultura centrada no cumprimento de objetivos e orientada para a execução de tarefas. Por fim, a cultura de apoio é mais orientada para as pessoas, baseando-se num clima de confiança mútua entre o indivíduo e a organização. Neste tipo de cultura, as pessoas acreditam que são valorizadas como seres humanos, e não como peças de uma máquina ou meros contribuintes para uma tarefa.

Procurou-se, em seguida, e de acordo com o modelo descrito, que adota a metodologia proposta por Sousa (2006), conhecer o tipo de cultura organizacional predominante no concelho de Almada. Constata-se que, em doze dos A/ENA do concelho de Almada, sobressai uma cultura de realização da organização, orientada essencialmente para a consecução de objetivos, os quais são participados e partilhados. Em seis Agrupamentos/Escolas Não Agrupadas, a escolha predominante relaciona-se com uma cultura burocrática, orientada essencialmente para cumprimento dos diplomas legais, pouco apelativa à participação e inovação. Por fim, em dois dos Agrupamentos/Escolas Não Agrupadas, os dados recolhidos denotam a existência de uma cultura de apoio, orientada principalmente para a satisfação dos profissionais. Em nenhum dos A/ENA se verificou a existência de uma cultura de tipo autocrático, fortemente assente no exercício do poder.

Comparando a percentagem de escolha da opção "sempre" nas questões de sinalização de dinâmicas com a comunidade ${ }^{6}$, verifica-se que os A/ENA com um tipo de cultura de realização apresentam valores superiores $(29,2 \%)$, contrastando com aqueles caracterizados por uma cultura de apoio $(5,4 \%)$ ou por uma cultura burocrática, nos quais a sinalização de relacionamento com a comunidade é quase inexistente $(0,8 \%)$. Ou seja, a afirmação mais intensa de promoção de relações com a comunidade parece tender a ser mais frequente nas organizações com uma "cultura de realização".

Constata-se ainda a existência de uma relação entre: por um lado, a tipologia das unidades orgânicas e o número de escolhas relacionadas com a realização de projetos, atividades e parcerias locais; e, por outro, aquela tipologia e a intensidade com que estas realizações são implementadas. De 
facto, é no conjunto das escolas secundárias que mais frequentemente os inquiridos declaram procurar "sempre" estabelecer articulações, seja com a autarquia, seja com outras instituições de ensino e instituições locais. Do mesmo modo, verifica-se que os A/ENA com cursos de educação e formação e cursos profissionais têm dinâmicas mais frequentes de articulação com a comunidade, nomeadamente no que respeita a: divulgação da sua imagem e oferta junto da comunidade; concretização de fontes de financiamento alternativo junto da comunidade; desenvolvimento de projetos em conjunto com a autarquia; coordenação de atividades com a rede social local; e intenção de reforço do relacionamento com a comunidade.

Contudo, é nos A/ENA inseridos no programa dos Territórios Educativos de Intervenção Prioritária (TEIP), localizados em meios socioeconómicos desfavorecidos, que se verifica de um modo mais intenso a sinalização da opção "sempre" pelos inquiridos, no sentido do estabelecimento mais ativo de dinâmicas com a comunidade e respetivas instituições. Salientam-se, neste domínio: o incentivo para a constituição da APEE; a disponibilização de recursos com vista ao funcionamento da APEE; a coordenação com instituições visando a sinalização e intervenção junto de jovens em situação de risco; e a solicitação de instalações (a instituições, por parte das escolas) para a concretização de atividades. Este facto justifica-se, à luz do Despacho 147-B/ME/96, porque, ao criar os TEIP, se propõe como medida o estabelecimento de relações de parceria, por parte da escola, "com outras entidades que concorram para a existência de uma efetiva articulação de espaços e recursos e para a construção de uma efetiva igualdade de oportunidades de formação" (Bettencourt et al., 2000, p. 179).

Por fim, sublinhe-se que não se verificou existir qualquer relação entre a antiguidade em cargos de gestão e a intensidade da dinâmica estabelecida com a comunidade.

Em síntese, o estabelecimento de interações com a comunidade educativa, para além de se relacionar com uma cultura de escola centrada no cumprimento dos objetivos e na realização das tarefas, parece ser fortemente influenciado, nuns casos, pela inclusão das escolas em medidas políticas específicas que permitem usufruir de recursos adequados à potencialização daquelas (por exemplo, os TEIP), sendo, noutros casos, o resultado da dinâmica das próprias escolas para assegurar atividades e projetos em 
articulação com a comunidade congruentes com a oferta formativa específica dessas mesmas escolas.

\section{Nota Conclusiva}

Tal como se referiu anteriormente, o presente artigo reporta dados da fase exploratória de uma pesquisa de doutoramento, constatando-se que a estrutura de Agrupamento/Escolas Não Agrupadas (inquiridas) parece convergir com o perfil geral a nível nacional se tivermos por referência o número de alunos e sua distribuição pelos diferentes níveis e ciclos de escolaridade.

$\mathrm{Na}$ fase exploratória, torna-se possível evidenciar, relativamente às escolas do concelho de Almada, alguns traços caracterizadores da relação das escolas com as comunidades envolventes. Começamos por destacar que a maioria dos Diretores aprecia a presença da comunidade no Conselho Geral, reconhecendo a estes elementos um envolvimento significativo e um contributo para a potencialização de parcerias educativas. Genericamente, todas as escolas manifestam a intenção de reforçar a relação com a comunidade educativa, embora não considerem esta linha de atuação uma prioridade, apesar das alterações de gestão estratégica introduzidas pela legislação. Consequentemente, apenas um número reduzido de escolas afirma pretender que estas sejam também um recurso educativo da comunidade local.

Os dados recolhidos permitem também evidenciar que 0 estabelecimento de relações da escola com a comunidade envolvente parece ter origem, essencialmente, na atuação da Direção das escolas, não surgindo frequentemente como um plano assumido e delimitado pelos órgãos de gestão escolar na sua globalidade. É também relevante referir que os principais atores da comunidade educativa considerados pelas escolas são os pais e encarregados de educação, individualmente considerados ou nas suas estruturas associativas de representação. Por um lado, consideramos que este resultado pode indiciar a existência de um entendimento muito circunscrito da diversidade de grupos, recursos e atores inerentes a qualquer comunidade envolvente de uma escola. Por outro lado, assinalamos que as Associações de Pais e Encarregados de Educação têm vindo a constituir-se 
de modo mais intenso recentemente e na sequência, quer do novo modelo de administração e gestão das escolas portuguesas, quer da necessidade de assegurar e dinamizar atividades de enriquecimento curricular e componente de apoio à família, sobretudo no pré-escolar e $1^{\circ}$ ciclo.

Adicionalmente, verificou-se que o tipo de cultura organizacional, a tipologia da escola, as dinâmicas de funcionamento e a oferta formativa inerentes a cada um dos tipos de escola estão relacionados com a iniciativa das escolas em se articularem mais intensamente com a comunidade envolvente, assim como a inclusão da escola em medidas específicas de política educativa como os TEIP contribui para a promoção desse tipo de relacionamento entre escola e comunidade.

Este conjunto de traços caracterizadores da relação das escolas com as comunidades envolventes converge com as tendências identificadas na primeira parte deste artigo, nomeadamente configurando, em termos globais, uma lógica de abertura à comunidade possivelmente em transição para uma lógica de parceria entre escola e comunidade que não é (ainda?) claramente identificável. Ou seja, existem indícios que apontam para a valorização deste tipo de relações por parte dos Diretores de escolas do concelho de Almada, mas constata-se o caráter ténue e circunscrito dessa relação, adivinhando-se a existência de significativas dificuldades e obstáculos nestas dinâmicas.

Assim sendo, torna-se pertinente, em nosso entender, desenvolver uma abordagem de um caso específico que permita a caracterização e compreensão mais aprofundada das dificuldades e resistências à dinamização das relações escola-comunidade, assim como a exploração de modalidades de promoção dessa mesma relação. Nesse sentido, teve já início uma segunda etapa da pesquisa de doutoramento, centrada no caso de uma escola situada no concelho de Almada. Pretende-se, por um lado, produzir um conjunto de recomendações que possam ser úteis para dinamizar a relação escola-comunidade, a partir do estudo de um caso concreto e da análise das resistências, dificuldades, potencialidades e possibilidades que esse mesmo caso encerra. Por outro lado, pretende-se evidenciar que estes processos se configuram como oportunidades educativas (formais, nãoformais e informais) para os vários atores envolvidos na relação escolacomunidade. 
Na nossa perspetiva, a relação entre escola e comunidade educativa, para além de constituir uma questão de gestão e administração escolar, podendo ser abordada numa perspetiva de compreensão da(s) lógica(s) territorial(is) de inscrição espacial das políticas e práticas educativas, constitui ainda uma temática que deve ser explorada no plano dos seus sentidos e efeitos para a/na experiência e trabalho educativo de professores, alunos e outros atores envolvidos, tal como também parece sugerir Canário (2005). trabalho de pesquisa relatado neste artigo constitui, afinal, o ponto de partida de um projeto de investigação educativa mais amplo e em desenvolvimento.

\section{Notas}

1 Esta pesquisa, com o título "Escola Con(vida): um estudo sobre a construção da comunidade educativa" , foi recentemente concluída pela doutoranda Teresa Varela sob a orientação de Mariana Gaio Alves.

2 Dados consultados em www.cm-almada.pt (acesso em 7 de junho de 2011).

3 Educação em números, GEPE, 2010.

4 Publicado no Diário da República de 27 de julho de 2004.

5 Publicado no Diário da República de 6 de janeiro de 2006.

6 Consideram-se como "questões de sinalização de dinâmicas com a comunidade" um conjunto de doze perguntas que incidem sobre: o desenvolvimento de projetos com a comunidade local e com a autarquia; formas de articulação desenvolvidas com outras instituições de ensino e com a rede social local; a partilha de recursos ou a intenção de reforçar a relação escola-comunidade. Assumiu-se o pressuposto de que as respostas "sempre", por parte das escolas, indiciam uma intenção forte de estabelecer relações com a comunidade envolvente.

\section{Referências}

Afonso, A. (1999). Metodologia para a celebração dos contratos de autonomia. In C. C. Ramos, H. Roque \& J. M. Alves, Que fazer com os contratos de autonomia (pp. 14-26). Porto: Edições Asa.

Alves, M. G. (2010). A educação no contexto das sociedades e das políticas centradas na aprendizagem ao longo da vida: Construção teórico-metodológica de um projeto de pesquisa. In M. G. Alves (Ed.), Aprendizagem ao longo da vida e políticas educativas europeias: Tensões e ambiguidades nos discursos e nas práticas de estados, instituições e indivíduos (pp. 5-24). Caparica: Edições UIED. 
Alves, N., e outros (1997). Escola e comunidade local. Lisboa: Instituto de Inovação Educacional.

Arroteia, J. C., Pardal, L. A., Costa, J. A., Martins, A. M., \& Neto Mendes, A. (1997). Gafanha da Nazaré: Escola e comunidade numa sociedade em mudança. Lisboa: Instituto de Inovação Educacional.

Bettencourt, A. M., Sousa, M., Fernandes, M., Costa, J. A., Sousa, L., Mendes, A., \& Sarmento, M. J. (2000). Territórios educativos de intervenção prioritária. Lisboa: Instituto de Inovação Educacional.

Branco, L. (2007). A escola comunidade educativa e a formação dos novos cidadãos. Lisboa: Instituto Piaget.

Canário, R. (2005). O que é a escola? Um "olhar" sociológico. Porto: Porto Editora.

CNE (2010). Parecer sobre a avaliação externa das escolas. Diário da República, 2. ${ }^{a}$ Série.

Dias, N. (2003). Políticas educativas e dispositivos de territorialização: Da escola aberta à comunidade à escola em parceria (Dissertação de mestrado). Faculdade de Psicologia e Ciências da Educação da Universidade do Porto, Porto, Portugal.

Epstein, J., \& Sanders, M. (2000). Connecting home, school and community: New directions for social research. In M. Hallinan (Ed.), Handbook of the Sociology of Education (pp. 285-306). New York: Kluwer Academic.

Eurydice (2007). Autonomia das escolas na Europa. Políticas e medidas. Lisboa: Unidade Europeia da Rede Eurydice.

Ferreira, F. I. (2003). O estudo do local em educação. Dinâmicas socioeducativas em Paredes de Coura (Dissertação de doutoramento). Universidade do Minho, Braga, Portugal.

Formosinho, J. (2007). A autonomia das escolas em Portugal (1987-2007). In Atas da Conferência "As escolas face a novos desafios". Lisboa: Inspecção-Geral da Educação.

GEPE (2010). Educação em números. Portugal 2010. Lisboa: Gabinete de Estatística e Planeamento da Educação (GEPE) do Ministério da Educação.

Lima, L. (1998). A escola como organização e o partenariado na organização escolar. Braga: Universidade do Minho - Instituto de Educação e Psicologia.

Lima, L. (2009). A democratização do governo das escolas públicas em Portugal. Revista de Sociologia da Faculdade de Letras da Universidade do Porto, 19, 227-253.

Lima, L., Pacheco, J., Esteves, M., \& Canário, R. (2006). A educação em Portugal (1986- 2006). Alguns contributos de investigação. Lisboa: Conselho Nacional de Educação.

Lopes, A (2003). Parceria(s) da escola rural com parceiros locais: Uma proposta para (re)pensar uma escola rural (Dissertação de mestrado). Faculdade de Psicologia e Ciências da Educação da Universidade do Porto, Porto, Portugal.

Marques, E. (2003). Envolver para desenvolver - Um estudo de caso sobre as parcerias educativas (Dissertação de mestrado). Faculdade de Ciências e Tecnologia da Universidade Nova de Lisboa, Lisboa, Portugal. 
OCDE (2007). Improving school leadership - Country background report for Portugal. Disponível em http://www.oecd.org/dataoecd/44/56/40710632.pdf (acesso em 18 de dezembro de 2011).

Rodrigues, S. (2008). Do domínio simbólico ao domínio das dinâmicas: Redes de parceria local da Alta Lisboa (Dissertação de mestrado). ISCTE, Lisboa, Portugal.

Silva, P. (2006). Pais-professores: Reflexões em torno de um estranho objeto de estudo. Revista Interações, 2, 268-290

Sousa, F. (2006). Os comportamentos nas organizações. Lisboa: Editorial Verbo.

Sousa, R. (2000). Município e autonomia das escolas. In Atas do Seminário "Autonomia, contratualização e município". Braga: Cadernos Escolas e Formação.

Tavares, A. (2007). Herança cultural e desenvolvimento local. Das escolas isoladas aos centros educativos (Dissertação de mestrado). Faculdade de Psicologia e Ciências da Educação da Universidade do Porto, Porto, Portugal.

Zay, D. (1996). Das noções de abertura da escola e de comunidade educativa à de parceria. Estudo da escola. Porto: Porto Editora. 
BUILDING THE RELATIONSHIP SCHOOL-EDUCATIONAL COMMUNITY: AN EXPLORATORY APPROACH IN THE MUNICIPALITY OF ALMADA

\section{Abstract}

This article discusses the relationship between schools and the educational communities to which they belong. In the first part, the issue is framed and analysed considering the evolution of organizational models of the Portuguese educational system; we also consider several contributions from research on the theme produced mainly in Portugal. The second part presents empirical data from a survey conducted throughout a questionnaire completed by all schools in the municipality of Almada. This survey corresponds to the exploratory stage of a Ph.D. research. The concluding note includes the systematization of the reflection produced in the article and points out future lines of research concerning the relationship between school and local communities.

Keywords

School management; Educational systems; Local communities

CONSTRUIRE LA RELATION ÉCOLE-COMMUNAUTÉ ÉDUCATIVE: UNE APPROCHE EXPLORATOIRE DANS LA MUNICIPALITÉ D'ALMADA

Résumé

L'article se concentre sur le thème de la relation entre l'école et les communautés locales. Dans la première partie, la question est encadrée et analyse en considérant l'évolution des modèles d'organisation du système éducatif portugais et des nombreuses contributions de la réflexion et de la recherché sur le thème, produite principalement au Portugal, mais aussi ailleurs. La deuxième partie présente des données empiriques obtenues à partir d'un questionnaire d'enquête rempli par tous les établissements scolaires dans la municipalité d'Almada. Ceci correspond à l'étape 
exploratoire d'une recherché de doctorat. Pour conclure, on systématise des résultats de la réflexion produite dan l'article et on identifie des pistes de recherché qui permet une exploration plus poussée de la relation écolecommunauté locale.

Mots-clé

Gestion scolaire; Système éducatif; Communautés locales

Recebido em Dezembro/2011 Aceite para publicação em Julho/2012 Universidade Nova de Lisboa, Quinta da Torre, 2825-516 Caparica, Portugal. E-mail: mga@fct.unl.pt; Telef.: 212948383 